\title{
Como Preparar Um Relato De Caso Clínico
}

\section{How To Prepare A Clinical Case Report}

\author{
Prof. Doutor Júlio Aragão \\ Prof. Doutor Mauro Tavares
}

Artigo

Original

Original

Paper

"É fundamental diminuir a distância entre o que se diz e o que se faz, de tal forma que, num dado momento, a tua fala seja a tua prática..”

Paulo Freire

\begin{abstract}
Palavras-chaves:
Resumo

Relatos de Casos

Profissionais de saúde lidam diariamente com casos raros, difíceis,

Estudos de Casos interessantes ou de evolução pouco comum, mas infelizmente poucos se interessam em relatá-los. O relato de casos é uma ferramenta de fundamental importância como iniciação à produção científica e frequentemente é

Indicadores

de Produção

Cientifica. subestimado como tal. No presente artigo, discorre-se sobre a escolha, preparo, redação e submissão de um relato de caso a um periódico de forma a instrumentalizar profisssionais de saúde e estudantes da área nesse tipo de empreitada.
\end{abstract}

Abstract

Health professionals deal with rare, difficult, interesting or uncommonly developed cases on a daily basis, but unfortunately, only a few bother to report such cases. Case report is a very important tool in initiating a scientific productionand it is frequently underestimated. In the present work choosing, preparing, writing e submitting a case report are discussed in a way to develop such skills by health professionals and students.
Key words:

Case report

Case studies

Scientific

Publication

Indicators

\section{Introdução}

O relato de caso é considerado por alguns autores como a mais simples forma de produção científica. Em um momento em que a produção científica é tão valorizada na comunidade acadêmica, a publicação de um caso clínico ou de uma pequena série de casos pode ser uma importante ferramenta de aprendizagem e de contato com a produção científica (BRODELL, 2000).

O momento inicial para a publicação de relatos de casos clínicos começa a partir do contato de um profissional de saúde (ou estudante) com um paciente portador de uma enfermidade rara ou de interesse acadêmico, prosseguindo durante toda a vida profissional. Embora casos raros sejam frequentemente relatados, a raridade não é condição sine qua non para um relato de caso. O relato de um caso de uma doença frequente, com aspectos de interesse clínico ou evolução incomum, pode também ser relatado e muito bem aproveitado pela comunidade acadêmica. Casos que envolvam dilemas éticos, morais ou situações com implicações legais podem também ser relatados independente da raridade da patologia.

Profissionais e estudantes de diferentes áreas práticas recebem ou manejam, 
com frequência, casos como os que citamos acima, mas, infelizmente, por não se sentirem suficientemente instrumentalizados para a preparação de um manuscrito, deixam passar a oportunidade de relato. No presente trabalho, procuramos discorrer sobre as diferentes etapas necessárias ao preparo de um relato pertinente, conciso e de qualidade técnica.

Preparando um relato de caso

O caso a ser relatado geralmente é um caso de difícil resolução ou diagnóstico, podendo, em alguns casos, ter algum aspecto além do puramente biomédico que o torne de interesse. Cabe lembrar que o conceito de raridade é relativo ao tempo e espaço (por exemplo, na década de 70 um caso de dengue no Município do Rio de Janeiro poderia ser considerado raro). Conversar com colegas mais experientes que já tenham relatado casos também pode ser de muita valia nesse momento (YOSHIDA, 2007).

O consentimento do paciente para o relato é imprescindível e deve ser obtido por meio formal, ou seja, pela assinatura de um Consentimento Informado pelo paciente ou seu representante legal. A ausência desse documento acarretará na impossibilidade de aceitação pelo comitê de ética local e a consequente rejeição do manuscrito pela maioria dos periódicos científicos.

Obtido o consentimento, a colheita de dados relativos ao caso propriamente dito é o passo seguinte. Os dados devem ser concatenados em ordem cronológica de forma a situar a queixa ou motivo pelo qual o paciente procurou atendimento, sua história clínica, exame físico, exames complementares e evolução durante a terapêutica ou terapêuticas realizadas. Sempre que disponíveis e pertinentes ao assunto, fotos do paciente (que não permitam sua identificação) e de exames de imagem deverão ser obtidas.

A revisão da literatura sempre deverá ser individualizada quanto aos aspectos que estão sendo relacionados. Um caso cirúrgico que apresenta complicação rara deverá ter a revisão mais focada neste aspecto, e não na técnica cirúrgica utilizada ou nas indicações da cirurgia, por exemplo. Da mesma forma, casos muito raros podem apresentar relatos mais escassos, dificultando a pesquisa do assunto e reduzindo o número de citações. As bases de dados mais disponíveis no nosso meio são Lilacs, Medline, Pubmed e até mesmo dispositivos de procura da internet podem ser ferramentas de muito valor (ANWAR et al, 2004). Embora a utilização de artigos científicos seja vasta, não devem ser esquecidos os livros, principalmente no que tange a parte conceitual da patologia em questão.

De posse de consentimento, relato completo e uma revisão razoável da literatura é hora de finalmente escrever. Comece pelo título, geralmente o nome da patologia seguido de dois pontos e "relato de caso" (por exemplo: "Síndrome de Potter: relato de caso" ou ainda: "Aspectos éticos da prescrição de contraceptivos em adolescentes: relato de caso"). A organização do manuscrito é bem simples e geralmente é subdivida peal maioria dos periódicos em três partes: Uma introdução, o relato de caso, propriamente dita, e a discussão.

\section{Preparando O Relato De Caso}

Ao escrever a introdução, pense em ser conciso e apenas apresentar ao leitor o que de mais importante e relevante há sobre o assunto e, principalmente, sobre os aspectos que você quer abordar no caso. Geralmente 03 ou 04 parágrafos serão suficientes. Lembre-se que quaisquer relações ou inferências com o caso em tela devem ser alocadas na discussão. Embora o uso de objetivos não seja obrigatório, o último parágrafo da introdução pode ser dedicado a este fim, algo como "O objetivo do presente relato é ressaltar a importância dos aspectos relativos ao diagnóstico precoce da Síndrome de Potter e seu manejo obstétrico adequado".

O texto então passa ao relato com suas nuances, dentro da narrativa cronologia e organizada já proposta na coleta. Apesar de se tratar de um texto técnico, evite abreviações excessivas que podem ser óbvias para alguém de uma determinada área mas completamente enigmáticas para outros leitores. Mantenha a narrativa em um desenrolar constante até o desfecho do caso.
A discussão
(em alguns 
periódicos, conclusão) é então o momento de contrapor o que há de mais interessante da sua revisão bibliográfica com os seus achados práticos. Cabe mostrar todos os aspectos diagnósticos encontrados assim como os não encontrados, que devem ser apontados quando você achar relevante. Os achados e suas frequências, relatadas na literatura, abordagens terapêuticas realizadas e possíveis, tudo isso pode ser explorado, mantendo-se firme no caminho da concisão, pois, não se pretende escrever um tratado sobre o assunto, mas, simplesmente, um relato de caso. As citações devem ser sempre feitas de acordo com o proposto pelo periódico a que você pretende submeter o caso. Não utilize citações demais, mas aproveite o que de melhor cada uma delas possa oferecer. Não existe número certo para citações, mas tente permanecer entre 15 e 30 referências (FOX, 2000).

A maioria dos periódicos exige que os manuscritos apresentem resumos de aproximadamente 200 a 300 palavras, acrescidas de palavras-chave acompanhadas de abstract e key-words em inglês. Em relação às palavras chave, é de muito bom tom que estejam no formato Medical Subject Headings (MeSH) ou Descritores em Ciências da Saúde (DeCS). Este formato pode ser consultado diretamente no sítio da Biblioteca Virtual em Saúde (www. bireme.br), agilizando ainda mais o processo.

Por último, uma nota a respeito da autoria. Embora existam muitos profissionais que tenham assistido ao caso, o relato não precisa incluir todos eles, mas apenas os principais. Evite fazer com que o seu relato apresente um número grande de autores, pois estamos falando de uma produção simples, que não deveria exigir uma equipe de pesquisa muito extensa.

\section{Considerações Finais}

O relato de caso, frequentemente, é relegado ao segundo plano, como uma produção científica de menor qualidade. Todavia, cremos que a sua realização pode ser uma importante ferramenta no fomento de atividades científicas em diversos ambientes (acadêmicos ou não) com resultados proveitosos para os profissionais envolvidos e a comunidade científica como um todo.

\section{Bibliografia}

FOX R. Writing a case report: an editor's eye view. Hospital Medicine. v.61(12):863-4, 2000.

ANWAR, R; KABIR H; BOTCHU R; KHAN S A; GOGI N. How to write a case report Students British Medical Journal.v.12:45-88 February, 2004

BRASIL, Biblioteca Virtual em Saúde. Descritores em Ciências da Saúde, 2005 documento disponível em $<$ http://decs.bvs.br/>.Acessado em: 28 nov. 2008.

YOSHIDA, W B. Redação do relato de caso. Jornal Vascular Brasileiro. v. 6, n. 2, jun. 2007 . Disponível em: $\quad<$ http://www.scielo.br/scielo. php? script $=$ sci_arttext\&pid $=\mathrm{S} 1677$ $54492007000200004 \quad \& \operatorname{lng}=p$ t\&nrm $=$ iso $>$. Acessado em: 28 nov. 2008.

BRODELL RT. Do more than discuss that unusual case: Write it up. Postgraduate Medicine.v.108 (2), 2000

Endereço para Correspondência:

Profa Rozana Aparecida de Souza

Curso de Serviço Social

rozana.souza@foa.org.br

Centro Universitário de Volta Redonda

Campus Três Poços

Av. Paulo Erlei Alves Abrantes, $n^{\circ}$ 1325,

Três Poços - Volta Redonda / RJ

CEP: 27240-560 